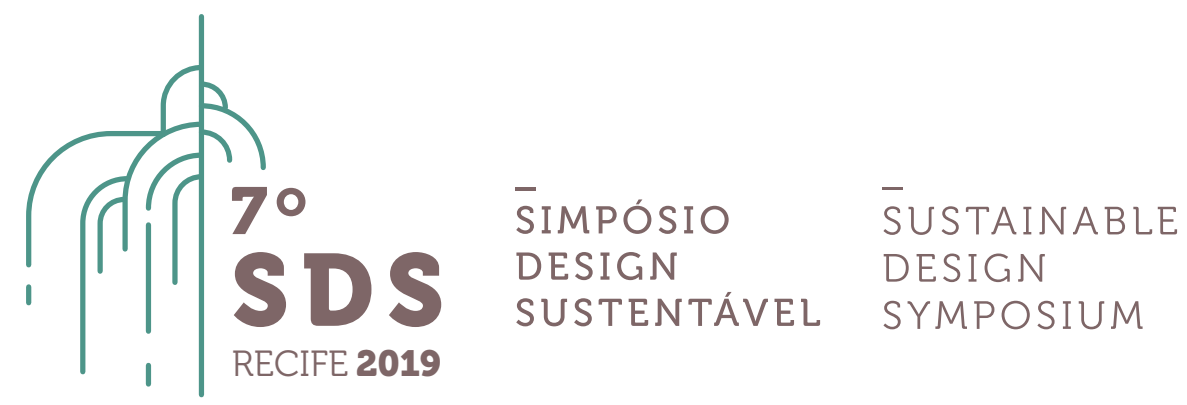

\title{
Possible impacts when design meets its local dimension
}

\author{
Carla Paoliello ${ }^{1, a}$ \\ ${ }^{1}$ Ph.D., Lisbon University, Fine Arts Faculty, carlapaoliello@gmail.com
}

\begin{abstract}
What is the meeting point between the design and its local dimension? How does the partnership between designers and artisans work? What is the impact of designing with and not for someone? These are some of the questions that guide this paper. It aims an impact analysis when design, especially the product one, finds craftsmanship. It is a theoretical evaluation that considers the social, cultural, economic, and environmental areas.
\end{abstract}

Keywords. Impact, Design, Craft, Local development.

\section{Introdução}

É indubitável a importância do design no mundo contemporâneo. Trata-se de uma ferramenta indispensável no desenvolvimento da economia principalmente de países classificados como 'em desenvolvimento' (PATROCÍNIO e NUNES, 2015). Existe também o posicionamento que defende o papel do design como promotor de qualidade de vida e facilitador de aspectos econômicos, tecnológicos, sociais, culturais e ambientais.

Mais recentemente, este foi percebido como fator de troca, como relação. No contexto no qual a prática do design está expandida da necessidade econômica ou apenas como elemento político governamental para o campo de projeto de experiências e processos, visto como dinamizador de práticas colaborativas, aparece um design que concilia híbrida ou paralelamente a produção de dimensão industrial com a experimentação autoral. Aparecem novas possibilidades de atuação. Surge o designer sob a forma de consultor, externo ou integrado em equipas multidisciplinares, que descortina identidades. Surge o profissional indutor de mais-valias que busca a renovação e a atualização do seu modo de fazer e de pensar e atua em interface com outras áreas na sociedade atual, nomeadamente no fazer local. Como 'fazer local' entende-se aquele conjunto de ações e, consequentemente, seus produtos que são demarcados por características locais e regionais, expressão de um coletivo, de um povo, ou de um único artífice(SENNET,T 2009). Os objetos desta produção conseguem carregar em si as particularidades da cultura local.

Considera-se que os produtos do 'fazer local' são exemplos de uma cartografia geográfica, social e cultural de maneira que não existe dissociação entre as pessoas inseridas neste processo de produção e a localidade a qual elas pertencem. Nesta definição, faz-se fundamental a escolha de materiais acessíveis, o domínio das técnicas utilizadas, a escolha por processos de produção sustentáveis e da pertinência dos equipamentos e 
instrumentos usados. Prioriza-se também a valorização do contexto socioeconômico e considera-se as histórias, memórias, crenças, tradições e simbolismos próprios dos produtores. (PAOLIELLO, 2016)

Qual é o ponto de encontro entre o design e sua dimensão local? Qual o impacto do projetar com e não para. Como ocorre a parceria entre designers e artífices? Estas são algumas das perguntas que norteiam este artigo cujo objetivo é a análise dos possíveis impactos quando o design, em especial o de produto, encontra o artesanato.

Para o desenvolvimento deste texto e alcance do proposto, foram coletados e analisados dados de natureza primária e secundária, o que também classifica essa investigação como bibliográfica e de campo, com relação aos meios utilizados. O primeiro passo foi uma procura documental com levantamento de informações em livros, revistas acadêmicas, dissertações, teses e jornais, tanto no meio impresso quanto eletrônico sobre o impacto de relações diversas. 0 segundo passo foi a avaliação dos projetos de parcerias entre artífices e designers, entendimento de seus objetivos e das possíveis alterações almejadas em documentos, catálogos, sites de divulgação e entrevistas com artesãos, designers e agentes financiadores destes projetos.

\section{Desenvolvimento}

Entre 1950 e 1990, a arquiteta Lina Bo Bardi e o designer Aloísio Magalhães refletiam e fomentaram o desenvolvimento da produção brasileira. Ambos percebiam que atuavam na sociedade mais como articuladores do que como criadores e exaltavam a riqueza brasileira. Tanto Lina quanto Aloísio concordavam que o desenvolvimento do país aconteceria a partir do encontro da cultura com as tecnologias geradas na e para a realidade nacional. É possível ter nascido com eles o binômio design-artesanato; com certeza é a partir dos seus textos que inicia-se a compreensão do papel do design hoje no Brasil.

No entanto, foi apenas a partir da década de 90, que o SEBRAE e outras instituições, incluindo nesta lista algumas universidades, começaram a atuar em projetos de desenvolvimento local com o intuito de fomentar o artesanato de forma integrada, ou seja, enquanto setor econômico sustentável que valoriza a identidade cultural das comunidades e promove a melhoria da qualidade de vida, sempre com vista à ampliação da geração de renda e de postos de trabalho.

Neste momento, o fazer artesanal informal foi entendido como uma grande área de atuação e uma forma de inserir o público disperso numa rede estruturada de relações. O design, com suas práticas metodológicas, técnicas e simbólicas, foi o ponto fundamental escolhido para se conseguir: identificar demandas e ofertas; divulgar e criar acesso ao mercado; melhorar produtos, matérias-primas, técnicas e processos de gestão e de produção; capacitar produtores; agregar valor; e fortalecer a cultura local.

Até os dias de hoje, são inúmeros os projetos que envolvem: a comunidade da unidade de produção local e/ou o artífice e todo o seu contexto social, técnico, cultural e econômico; o designer que se apresenta como um facilitador que, em parceria, descortina a realidade existente, sua qualidade e beleza e que, individualmente, apresenta seu universo e história; e o agente financiador que pertence às instituições que fomentam estas parcerias.

Para Mascêne e Tedeschi (2010:37), responsáveis pelo 'Termo de referência: atuação do

\section{$7 \circ \mathrm{SDS}_{2019}^{\mathrm{RECHF}}$}


Sistema SEBRAE no artesanato', programas desta natureza devem "propor um conjunto de disciplinas, com conteúdos interconectados construindo uma sequência lógica, com exercícios de verificação de aprendizagem e um tempo de aplicação dos ensinamentos recebidos em sua prática cotidiana, construindo assim uma aprendizagem significativa".

Eles acreditam que a chave para qualquer mudança social está na educação. É por meio dela que se é possível desenvolver habilidades e capacidades para um determinado trabalho, encontrar um lugar na sociedade, e adquirir noção de pertencimento e de cidadania. Entretanto, frisam que "o processo educacional deve ser contínuo, sistemático e voltado para a realidade de cada contexto social" (MASCÊNE e TEDESCHI, 2010:48). Desta maneira faz-se necessário entender e monitorar esta realidade, suas metas e atores, através do levantamento, sistematização e processamento de dados, análise das informações e disseminação das conclusões e recomendações para uso e reflexão junto aos participantes. Como então se determina a valia ou o valor de algo?

A avaliação é uma possível resposta por ser um mecanismo de conhecimento e delimitação do alcance de um projeto, programa ou serviço capaz de verificar e questionar as dimensões existentes e o potencial transformador de uma determinada ação. Com uma boa avaliação tornase possível: "desconstruir ideias, alinhar conceitos, corrigir rumos, mudar prioridades, abrir mão de iniciativas que não se mostram frutíferas" (MINAYO, ASSIS e SOUZA, 2005:20), mesmo nos projetos marcados por fortes componentes socioculturais.

Deve-se aprofundar as reflexões para compreender cada projeto em sua totalidade. Tratase de um exercício metodológico capaz de conhecer e medir as informações disponíveis sobre os recursos físicos, humanos e materiais e sobre as formas de organização e funcionamento (normas e procedimentos). É preciso ter a ciência de que o todo contém as partes e que existe uma inseparabilidade e uma irredutibilidade da ordem e da desordem. Esta afirmação faz com que as avaliações sejam sempre atividades complexas nas quais "se encontram as relações entre universal e o particular; entre o global e o local; entre o coletivo e o individual; entre o todo e as partes; entre a análise e a síntese; entre as relações cêntricas, acêntricas e policêntricas" (MINAYO, ASSIS e SOUZA, 2005:34).

Estas autoras relatam sobre dois tipos de análise em especial. A primeira seria a avaliação de implantação na qual visa-se verificar o alcance de um programa para a população-alvo, monitorar sua sequência e a participação dos sujeitos envolvidos, avaliar a variabilidade do contexto organizacional e mensurar o custo de implementação. Em um segundo caso, é possível avaliar às atividades realizadas, incluindo os componentes técnicos e as relações interpessoais e analisar os resultados (os efeitos e os produtos) em acordo com os objetivos da intervenção. Esta seria a avaliação de resultados que visa dimensionar, qualitativa e quantitativamente, as diferenças entre o momento inicial e as metas atingidas ao final de uma intervenção. Em ambos os casos, uma descrição completa inicial faz-se importante. Deve-se considerar a filosofia da intervenção (objetivos e metas), o perfil de todos os atores envolvidos (designers, artífices e agentes financiadores), a forma de gerenciamento das atividades e os mecanismos de interação.

O impacto final é definido como as "mudanças duradouras ou significativas - positivas ou negativas, planejadas ou não - nas vidas das pessoas e ocasionadas por determinada ação ou série 
de ações" (ROCHE, 2002:37). No caso de avaliações de impacto, são considerados os insumos (inputs materiais, financeiros, humanos) que iniciam o processo. Estes devem ser disponibilizados em quantidade e qualidade adequadas às atividades a serem realizadas e devem estar coerentes com o propósito almejado. Ao final, são analisados os produtos (outputs) que correspondem aos serviços prestados e também conhecidos os resultados da intervenção (outcomes ou propósitos atingidos).

\title{
2.1 Impacto social
}

O impacto social é a mudança mensurável no bem-estar subjetivo de uma população em resultado direto de um projeto, programa ou política. Trata-se de entender como que as ações ou intervenções realizadas reforçam as habilidades e competências dos indivíduos envolvidos. Tratase também de compreender como se estabelece o processo de melhoria contínua a partir das parcerias estabelecidas.

A primeira seria a fase de diagnóstico, ou seja, de compreensão da realidade a partir da manifestação participativa dos envolvidos. Sugere-se destacar os principais problemas existentes ou que possam surgir, e também as potencialidades de cada ator social. Quais seriam os indicadores de processo a serem utilizados? Como medir o aumento da qualidade de vida, a equidade social e cultural? E ainda, como é possível empoderar os sujeitos sociais para que se tornem protagonistas do seu próprio desenvolvimento?

Medir o bem-estar é algo complexo e a diversidade nos aspectos sociais, econômicos e culturais dos envolvidos dificulta ainda mais o trabalho. Estudos no âmbito da psicologia que relacionam-se com as perspectivas teóricas dominantes em torno do bem-estar (BE) são os mais indicados. As pesquisadoras Mirlene Siqueira e Valquiria Padovam delimitam as concepções científicas sobre bem-estar em

\begin{abstract}
(...) duas perspectivas: uma que aborda o estado subjetivo de felicidade (bem-estar hedônico), e se denomina bem-estar subjetivo, e outra que investiga o potencial humano (bem-estar eudemônico) e trata de bem-estar psicológico. Na visão dos autores Ryan e Deci (2001), essas duas tradições de estudo refletem visões filosóficas distintas sobre felicidade: enquanto a primeira (hedonismo) adota uma visão de bem-estar como prazer ou felicidade, a segunda (eudemonismo) apoia-se na noção de que bem-estar consiste no pleno funcionamento das potencialidades de uma pessoa, ou seja, em sua capacidade de pensar, usar o raciocínio e o bom senso. (SIQUEIRA e PADOVAM, 2008:201)
\end{abstract}

Desta maneira, o bem-estar subjetivo (BES) constitui um campo de estudos para compreensão da qualidade de vida, criado para monitorar mudanças sociais e identificar as condições sociodemográficas, políticas e culturais que lhes estão associadas. É uma autoavaliação que considera concepções subjetivas como expectativas, valores, emoções e experiências prévias. Também são importantes ao BES: a autoestima (em que o próprio indivíduo se reconhece como tendo valor e sendo dotado de características positivas e negativas), a autoaceitação, a autoimagem e o autorrespeito.

Já segundo a professora e psicóloga Rosa Ferreira Novo, o bem-estar psicológico (BEP) é um conceito que "abrange a área da percepção pessoal e interpessoal, a apreciação do passado, o envolvimento no presente e a mobilização para o futuro, assumindo um carácter amplo e representativo do funcionamento psicológico positivo ao nível privado" (NOVO, 2005:185). Difere- 
se do anterior por ser orientado para a realização pessoal e desenvolvimento do ser.

Foi a pesquisadora Carol Ryff, a par das elaborações teóricas (1985, 1989a,b), que organizou a proposta de avaliação com seis dimensões do BEP: autoaceitação; autonomia; relacionamento positivo com outras pessoas; domínio do ambiente; propósito de vida; e crescimento pessoal.

Se for considerado o bem-estar no trabalho, este depende também de outras componentes adaptados pela mesma pesquisadora Siqueira em conjunto com Padovam (2008:206), a saber: satisfação no trabalho; envolvimento com o trabalho; e comprometimento organizacional afetivo.

Existe, também, a escala de funcionamento psicológico positivo (EFPP), desenvolvida por Merino e Privado, em 2015, e formada por onze recursos psicológicos: autoestima; resiliência; curiosidade; otimismo; autonomia; vitalidade; domínio do meio; propósito na vida; humor; desfrute; e criatividade.

Tem-se assim quatro propostas possíveis para se avaliar o bem-estar de uma dada população e todas utilizam da escala de resposta do tipo Likert com pontos que vão desde nunca ou discordo completamente a quase sempre, concordo completamente. As propostas são multidimensionais, sistémicas e intersectam-se entre si, instituindo um sistema complexo de avaliação e monitoramento. Sabe-se, no entanto, que o bem-estar é apenas um dos fatores a serem avaliados em função das intervenções que buscam a melhoria das vidas individuais e coletivas. Não é possível limitar o estudo apenas aos conteúdos reflexivos e realizados por parte de cada ator sobre si mesmo. A este, deve-se também integrar avaliações do âmbito cultural, econômico, e ambiental.

\subsection{Impacto cultural}

$\mathrm{Na}$ década de 1990, a Organização das Nações Unidas (ONU) criou o Índice de Desenvolvimento Humano (IDH), composto por três dimensões: a renda (medida pelo Produto Interno Bruto), educação (medida pelos anos de educação de adultos) e a saúde (medida pela longevidade). Para o pesquisador Júlio Aurélio, da Fundação Casa de Rui Barbosa, o IDH deveria levar em consideração mais um indicador: a cultura, definida em dois sentidos:

em seu sentido vasto (antropológico) como o conjunto de normas, valores, saberes,
crenças, modos de vida e práticas simbólicas que norteiam a conduta individual e
organizam o comportamento coletivo. E em seu sentido restringido (sectorial) como um
sector de atividade que organiza as diferentes manifestações da criatividade intelectual e
artística - passada e presente - e que inclui indivíduos, organizações e instituições
envolvidos em sua transmissão e renovação. (UNESCO, 2016:17)

Neste sentido, e de acordo com o Programa das Nações Unidas para o Desenvolvimento (PNUD), a cultura é entendida como constitutiva do desenvolvimento porque "a liberdade de escolher os valores que a gente acha que deve defender e a existência a que a gente deve almejar" [...] são decisivos para que "as pessoas possam viver da maneira que desejem".

Qual seria o papel que a cultura e os elementos simbólicos desempenham na sociedade, no desenvolvimento dos territórios e dos produtos? Como quantificar hábitos culturais e qualificar a mudança proveniente do encontro entre designer e artífice? Como que a atividade cultural 70 SDS $_{2019}^{\mathrm{RECIF}}$ 
enquanto atividade econômica contribui para a geração de riqueza e crescimento socioeconômico de um território? Faz-se necessário recordar que

o valor da cultura reside na produção e consumo de bens, serviços e atividades culturais, e no conhecimento que nós transmitimos uns aos outros através de símbolos que compreendemos e interiorizamos, para depois transformá-los e inovar. Esses símbolos compartilhados proporcionam um sentimento coletivo e de identidade, uma coesão social necessária para travar relações, tanto comerciais, quanto profissionais ou pessoais. (UNESCO, 2016)

A cultura então pode ser compreendida como parte do sector econômico, como meio de transmissão de conhecimento e de identidades e também como base da qualidade de vida, da coesão social, da resolução de conflitos e da redução de desigualdades. No caso das parcerias design-artesanato, existem três atores sociais com níveis de educação, linguagem, estrutura social, sistema de valores, filosofias e histórias particulares. Para que este encontro multicultural ocorra no sentido de enriquecer as ações propostas, faz-se importante haver abertura para aceitar a introdução de um saber externo e diferente ao inicial. Faz-se então necessário verificar se existe a capacidade de adaptação ao diverso.

Jiménez e Malgesini (1997) em seu 'Guía de conceptos sobre migraciones racismo e interculturalidad' mencionam que os fundamentos essenciais do multiculturalismo podem ser sintetizados de acordo com a aceitação das diferenças culturais; a defesa e reivindicação ao direito à diferença e de ser distinto em relação aos valores e crenças; e no reconhecimento do pluralismo.

A valorização da diversidade cultural parte do reconhecimento aberto das diferenças culturais, costumes, valores, comportamentos e atitudes de cada par. Parte-se do respeito pelos diversos saberes e perpetua-se nos valores de uma cultura existente que, de forma colaborativa, se transforma. Neste sentido, as parcerias estabelecidas no binómio design-artesanato devem ser emancipadoras, conceito base dos projetos do educador Paulo Freire e também de Jacques Rancière. Este último chegou a afirmar que "quem ensina sem emancipar, embrutece" (2002:30). Como um processo de libertação, as parcerias devem ser centradas nos sujeitos envolvidos que, em conjunto, são os produtores de conhecimento. As intervenções do design para o desenvolvimento local não se configuram apenas como um repasse de informações, ou um conjunto de ações técnicas e/ou de capacitação. Elas estão associadas à realidade vivida, com a história e a cultura de cada sujeito envolvido. Todos são mestres como descrito por Rancière (2002:17).

Os artesãos não devem se sentir superiores por serem detentores de habilidades específicas na produção de objetos e na manipulação das matérias-primas e dos conhecimentos tradicionais. Os designers por sua vez não podem ser também os únicos responsáveis pela promoção de inovações, melhoria da qualidade e atualização e inserção da produção no mercado. Os agentes financiadores não são apenas os que proveem o capital necessário para acontecimento do projeto.

Pela ótica de Freire, discutida e implementada nas práticas dos Círculos de Cultura (método pedagógico de educação popular idealizado pelo educador), as relações devem se destacar pelo respeito à cultura e ao saber do outro, o diálogo com os desejos e aspirações dos envolvidos, a valorização do seu contexto social, e ações com foco na transformação social. A conscientização é $7 \circ S^{\circ} S_{2019}^{\text {RECIF }}$ 
considerada portanto um conceito central das ideias freireanas e constitui-se como um "ato de conhecimento, (e) uma aproximação crítica da realidade" (FREIRE, 1980:25).

Para tal, as atitudes ativas, críticas, curiosas, reflexivas e participativas são fundamentais. 0 diálogo enquanto comunicação e intercomunicação entre sujeitos faz-se importante para se conhecer mais, para criar proximidade e haver a troca entre saberes. Entende-se que a função deste diálogo é "diminuir a distância entre a expressão significativa do técnico (designer ou agente financiador) e a percepção pelos camponeses (ou artífices) em torno do significado" (FREIRE, 2006:68). Trata-se de evitar a invasão cultural e desenvolver a interação cultural, ou melhor, de propiciar a interculturalidade.

Para a UNESCO (2014c), em concomitância aos princípios de Freire, a interculturalidade refere-se à existência e interação equitativa de diversas culturas e a possibilidade de gerar expressões culturais compartilhadas através do diálogo e do respeito mútuo. Respeito, tolerância, capacidade de dialogar e de trabalhar em conjunto, empatia, capacidade crítica são componentes já detectadas no item anterior e portanto poderão ser utilizadas as propostas de avaliação de bem-estar apresentadas ou a definida por Monteiro, Tavares, e Pereira (2012:63). Estes pesquisadores adaptaram para a realidade portuguesa a 'Escala de Medida de Manifestação de Bem-estar Psicológico (EMMBEP) que inclui 25 itens distribuídos por cinco subescalas: autoestima (4 itens), equilíbrio (4 itens), envolvimento social (4 itens), sociabilidade (4 itens), controlo de si e dos acontecimentos ( 4 itens) e felicidade (5 itens). Quanto mais elevado for o total obtido - dado pela soma das pontuações de todos os itens - maior será o bem-estar psicológico percebido.

Percebe-se ao fim que o ser humano é social, relacional, que se identifica e se realiza na comunicação interpessoal e que a cultura é uma dimensão indispensável ao seu desenvolvimento. No próximo item, avaliar-se-á a dimensão econômica que também é importante uma vez que somos seres interdependentes em busca de sobreviver e obter uma qualidade de bem-viver.

\subsection{Impacto econômico}

Atualmente acontece a valorização do fazer artesanal como atividade econômica enraizada na tradição local. Seus produtos passaram a ser consumidos como oposição à produção homogeneizada e global, são símbolos da necessidade de distinção, carregados de significados e valias identitárias e culturais. Aqui a economia do artesanato é entendida como explicado por Keller, ou seja,

como uma forma de economia dos bens simbólicos e folclóricos (Canclini, 2008), ou uma economia das singularidades (Karpik, 2007), e o produto artesanal como um objeto singular dotado de valor mercantil e simbólico (Bourdieu, 1996; 2004), sendo a cadeia do artesanato marcada pela particularidade de seu trabalho e de produto dotado de valores econômico-mercantis, simbólico-culturais e ecológicos (Guthman, 2009). (KELLER, 2014:333)

Canclini (1982:65) já afirmava que o artesanato traz consigo toda a expressão e fascínio simbólico explorado pelo capitalismo. Na comercialização de seus produtos, vê-se imbuído o valor cultural, para além do de uso e o de troca. Estes valores se transformam em uma mais valia econômica quando apresenta as características de uma localidade, enaltece as matérias-primas e técnicas que identificam determinado saber fazer e descortina a tradição e a história existente. É

\section{$7^{\circ} \mathrm{SDS}_{2019}^{\mathrm{REClF}}$}


claro que pode haver a atualização da produção artesanal com a substituição de um material que está a ficar escasso por outro mais abundante, pela mudança da técnica ou processo por um mais produtivo e mesmo pela alteração da forma ou função do objeto. Deve-se apenas ter o cuidado de preservar seu conteúdo cultural, ou seja, "interferir sem ferir" como disse Janete Costa.

Não é fácil atender às exigências de mercado e os critérios pré-estabelecidos de controle e de qualidade em uma produção artesanal, de caráter doméstico, secundário, complementar e descontinuado. $O$ desafio para a recuperação econômica é capacitar para o profissionalismo e a eficiência produtiva. É apostar na reorganização do trabalho e na formalização do mesmo já que quando ocorre uma melhoria na vida dos artífices, estes acabam por ficar na região de produção, e por consequência, ocorre o desenvolvimento deste território.

Uma solução encontrada é o comércio justo e solidário, definido como uma estratégia de empoderamento dos trabalhadores que estão à margem do modelo de mercado predominante. Para Tabosa, Fernandes, e Paiva Junior (2010:15), a comercialização de produtos que atenda a estes requisitos deveria se pautar na: utilização de práticas e metodologias que fortaleçam a ética, a transparência e a corresponsabilidade entre os diversos atores da cadeia de produção e comercialização; construção de relações solidárias; prática de remuneração e preços justos; consideração da diversidade cultural e valorização do conhecimento e da identidade das comunidades tradicionais nas transações comerciais; integração efetiva entre produtor e consumidor, para a construção coletiva do desenvolvimento sustentável; e na promoção de práticas de produção, comercialização e consumo que fortaleçam a justiça social, a preservação ambiental e a defesa da saúde humana.

Estas práticas podem ser enriquecidas com a formação de grupos de artesãos, como colocado por Vives (1983:144) quando afirmou que "favorecer a formação de cooperativas artesanais é também recurso a ser tentado, pois elas desempenhariam, hoje, em certa medida, o papel das corporações medievais". Trata-se de um importante instrumento para melhorar as condições de vida e de trabalho dos artífices uma vez que sua organização pode trazer vantagens que um artífice isolado não conseguiria ter: acesso à capacitação, consultorias, informações estratégicas e outros benefícios disponibilizados por órgãos de fomento a grupos formalizados. Temos assim a cooperação como na perspectiva marxiana, como "a forma de trabalho em que muitos trabalham juntos, de acordo com um plano, no mesmo processo de produção ou em processos de produção diferentes mas conexos" (MARX, 1975:374).

Um ponto que também vale destacar é a distribuição e a comercialização que segundo Borges (2011) são o gargalo de toda a produção artesanal. Escapar da figura do intermediário conhecido como 'atravessador', aquele comerciante que subvaloriza o produto feito, é fundamental, mesmo quando Belcher et al. (2005) relata que este pode ter um papel fundamental em: comunicar a informação entre os consumidores e produtores, proporcionar incentivo ao mercado, organizar o transporte, controlar a qualidade, adiantar crédito, consolidar volumes e suportar os riscos. Para Keller (2004:339-340), "as principais formas de escoamento da produção nos grupos estudados (associações e cooperativas) são: a venda direta de seus produtos em loja no comércio local (que se beneficia do fluxo de turistas); participação em feiras e exposições; e por meio de encomenda". Vale ressaltar que a participação em feiras e eventos normalmente acontece a partir do apoio de alguma agência de fomento ao artesanato. 
Como medir o impacto econômico quando ocorre a parceria designer-artesão? Como avaliar a situação inicial anterior à intervenção para compara-la com os aspectos no pós-ação? Trata-se de analisar o montante de bens e serviços finais criados (ótica da produção) e os rendimentos recebidos pelos fatores de produção (ótica de rendimento) durante um determinado período de tempo. Lemes (1996:68) afirma que o ideal é avaliar o lucro ou o resultado econômico, uma vez que só assim é possível "absorver e refletir as variações entre os componentes: produtividade, eficiência, satisfação, adaptabilidade e desenvolvimento, inclusive a própria sinergia entre eles". A recolha de informação efetua-se com base em recolha de informação documental e de campo, por via de questionários semiestruturados, entrevistas abertas, diários de campo e observação simples.

Ana Cristina Brito Arcoverde (2010:37) também afirma, no artigo 'Avaliação dos impactos sociais e econômicos dos empreendimentos solidários em Pernambuco', que no caso dos empreendimentos econômicos solidários devem ser "buscados os acréscimos de bem-estar, a percepção que os empreendedores possuem do próprio negócio e a qualidade da mudança em sua vida e na medida do possível no contexto do local".

Para mensurar os impactos econômicos na produção de empreendimentos sociais, Arcoverde (2010:39) investigou: a produção - as principais atividades desenvolvidas, os principais produtos, a divisão dos ganhos, a distribuição das tarefas e a organização da produção; a produtividade - as condições de trabalho, os equipamentos, ferramentas e serviços, os bens produzidos, o tempo necessário para produção; a renda - a composição da renda (benefício, aposentadoria, salário, aluguel), os valores em reais da renda familiar e per capita; o investimento - a participação dos sócios nos empreendimentos e os financiamentos; e os custos, caracterizados pelas dívidas adquiridas.

Esta autora também mensurou os impactos ideopolíticos, visando identificar as mudanças de espírito, a percepção da realidade, visão do mundo, consciência e ação política através: do aumento na qualidade de vida - pelo grau de satisfação no trabalho, do convívio familiar; do nível de empoderamento e politização - pelo acesso a serviços, visibilidade junto à comunidade do empreendimento do trabalho realizado e da participação em associações, sindicatos ou mesmo em outros empreendimentos.

São portanto muitas possibilidades de avaliação do impacto econômico, sendo fundamental perceber as organizações artesanais como uma alternativa para a geração de postos de ocupação e trabalho, como uma possibilidade de revalorização do saber local e dos bens materiais e imateriais que formam a cultura e a identidade territorial. Se antes era uma atividade marginal, hoje pode ser inserida no mercado, a contribuir para o crescimento econômico e o bemestar de muitos trabalhadores. No próximo item será tratado o aspecto ambiental nas parcerias design-artesanato.

\subsection{Impacto ambiental}

Para Cláudio Spadotto o impacto ambiental pode ser definido como

qualquer alteração das propriedades físicas, químicas e biológicas do meio ambiente, causado por qualquer forma de matéria ou energia resultante das atividades humanas que direta ou indiretamente, afetam a saúde, a segurança e o bem estar da população; as 
atividades sociais e econômicas; a biota e a qualidade dos recursos ambientais. (SPADOTTO, 2002:1)

Para a avaliação nos projetos de parceria entre designers e artesãos, complementa-se com outra definição uma vez que faz-se importante entender como que a atuação em conjunto altera a escolha dos materiais e das técnicas adotadas, como que o sistema de produção se modifica, quais inovações ocorrem e como que a influência do território aparece nos produtos desenvolvidos. Sobre este último ponto, vale destacar o peso que as indicações geográficas (IG) podem ter no processo.

O acordo da Organização Mundial do Comércio (OMC) sobre os Aspectos dos Direitos de Propriedade Intelectual (TRIPS), define as IG como instrumentos jurídicos que identificam um produto como originário do território de um determinado país, ou de uma região ou localidade desse território, onde a qualidade, reputação ou outra característica do produto seja essencialmente atribuída à sua origem geográfica.

Trata-se de um processo de padronização da qualidade, já que o produto começa a atender às exigências das legislações específicas do lugar onde é produzido. Entretanto, as IG diferem dos certificados de qualidade existentes uma vez que considera o meio geográfico, a matéria-prima e/ou técnica específica de um determinado local. Pela Instrução Normativa de número 25/2013, a IG pode ser constituída pela Indicação de Procedência ou pela Denominação de Origem.

Neste momento, alguns questionamentos surgem. Como as IG alteram os valores e a capacidade perceptiva em relação ao meio ambiente no qual a produção está circunscrita? Ocorre uma avaliação da consciência e compreensão da presença do homem no território? Criam-se ou reforçam-se os laços territoriais? Como pode ser medida a interpretação da localidade nos saberes e fazeres? Ou mesmo o fortalecimento do sentimento de pertença e o sentido de comunidade (auto reconhecimento)? É possível quantificar a valorização da identidade cultural e a autoestima local? Qual a inovação possível a partir do território?

Druzian e Nunes atentam para o possível ganho com a inovação se ela for entendida

\begin{abstract}
como a aplicação de novos conhecimentos ou invenções que resultam em melhoria ou modificação dos processos para a produção de novos bens. A melhoria desses processos produtivos pode ser a aplicação prática de um invento na transformação ou a melhoria de um determinado produto, mas pode também ser constituída pela reformulação dos processos de gestão do trabalho, o que pode conferir nova feição à organização interna do processo produtivo. (DRUZIAN e NUNES, 2012:422)
\end{abstract}

Acredita-se que os processos de identificação geográfica conseguem despertar sentimentos topofílicos (TUAN, 1980:129), ou seja, se forem realizadas ações de desenvolvimento da memória territorial e reconhecimento da sua importância histórica e cultural. A apresentação e o reconhecimento dos elementos locais, das matérias autóctones, da paisagem circundante são o caminho para perceber a importância deste selo (IG) e para se conseguir a melhoria na qualidade da vida dos envolvidos. A partir da percepção é possível ter consciência do ambiente no qual se está inserido e dos próprios atores. É que a percepção ambiental revela as interrelações entre homem e meio, incluindo as expectativas, satisfações, julgamentos e condutas.

Existe um modelo de identificação de percepção e consumo ecológico proposto por

\title{
$7^{\circ} \mathrm{SDS}_{2019}^{\mathrm{RECCF}}$
}


Brandalise (2008). Neste o pesquisador relaciona as variáveis ambiental, a percepção e o comportamento do consumidor. É um estudo que considera os conceitos de redução, reutilização e reciclabilidade dos recursos ambientais. Considera-se o produto desde a extração da matéria prima ao descarte e as variáveis são construídas a partir da Análise do Ciclo de Vida do produto (ACV). Considera-se também a redução de matéria prima, o consumo de energia, a geração de resíduos, bem como a maximização do uso sustentável dos recursos renováveis e o prolongamento da vida útil do produto.

O instrumento de coleta de dados de Brandalise (2008) é composto de quatro conjuntos de questões, a saber: o conjunto 01 do instrumento que trata da caracterização do pesquisado, o 02 que avalia a percepção ambiental, o 03 que abrange o consumo ecológico e o conjunto 04 que trata das etapas da ACV tanto quanto ao material usado quanto ao processo de produção, utilização, pós-utilização e descarte do produto.

Segundo este pesquisador, em um outro estudo realizado, a análise das respostas apuradas com a aplicação deste instrumento

\begin{abstract}
permite verificar se a população pesquisada percebe as características dos produtos considerados ecologicamente corretos. A percepção ambiental, decorrente da interpretação dos estímulos externos (informações) e internos (crenças, valores), somado às influências recebidas do meio externo, se reflete nas atitudes e comportamento de aquisição e consumo. (BRANDALISE e BERTOLINI, 2013:31)
\end{abstract}

\title{
3 Conclusão
}

Medir o impacto não é uma tarefa fácil. Trata-se de analisar o resultado de uma intervenção / parceria obtido na prática e que é percebido nas mudanças que ocorrem em função de tais ações. Existe uma relação de causa-efeito entre o impacto e a ação de um determinado projeto, existe também a interferência do tempo desta atividade (curto, médio ou longo prazo) e os efeitos esperados (positivos ou negativos) que podem ir ou não de encontro aos objetivos propostos inicialmente.

A melhor avaliação será aquela capaz de analisar as dificuldades e contradições ao longo do processo do projeto ou ao final deste de maneira a perceber a extensão e a intensidade com a qual os participantes se apropriaram dos objetivos, perseguiram as metas e observaram os aspectos de cada ação. Normalmente, quando os projetos são sócio-democráticos, verifica-se o aumento da autonomia dos atores envolvidos e do respeito pela diversidade cultural, além da geração de mais valias em todas as áreas - social, cultural, econômica e ambiental.

Neste estudo foram apresentados alguns dos prováveis impactos existentes em função do encontro design-artesanato. Uma fase seguinte será entender quais seriam os indicadores possíveis, entendidos aqui como instrumentos de mensuração e de estabelecimento de marcos conceituais e metodológicos para avaliar os efeitos das mudanças 'de progresso genuíno'. Será interessante analisar e listar os que consideram medidas simultâneas para a dimensão ambiental e cultural, o desempenho econômico, e a qualidade de vida (ou bem-estar) dos envolvidos.

\section{Referências}

ARCOVERDE, Ana Cristina Brito. Avaliação dos impactos sociais e econômicos dos 
empreendimentos solidários em Pernambuco. In: I Seminário Internacional \& III Seminário de Modelos e Experiências de Avaliação de Políticas, Programas e Projetos. Pernambuco: Universidade Federal de Pernambuco, 2010.

BELCHER, B., RUÍZ-PÉREZ, M., ACHDIAWAN, R.. Global patterns and trends in the use and management of commercial NTFPs: Implications for livelihoods and conservation. World Development, n. 33, p.1435-1452, 2005.

BORGES, Adélia. Design + Artesanato: o caminho brasileiro. São Paulo: Terceiro Nome, 2011.

BRANDALISE, L. T.; BERTOLINI, G. R. F. Instrumentos de medição de percepção e comportamento - uma revisão. Rev. Ciênc. Empres. UNIPAR, Umuarama, v. 14, n.o 1, p.7-34, jan./jun 2013.

BRASIL, Ministério do Desenvolvimento, Indústria e Comércio Exterior Instituto Nacional da Propriedade Industrial. Instrução Normativa n.o 25/2013.

CANCLINI, Nestor Garcia. As culturas populares no capitalismo. São Paulo: Brasiliense, 1982.

DRUZIAN, Janice Izabel; NUNES, Itaciara Larroza. Indicações geográficas brasileiras concedidas até julho 2012 e impacto sobre bens agrícolas e/ou agroindustriais. Revista Geintec - Gestão, Inovação e Tecnologia. v. 2, n.․ 4, p.413-426, 2012.

FREIRE, Paulo. Conscientização: teoria e prática da libertação: uma introdução ao pensamento de Paulo Freire. São Paulo: Moraes, 1980.

FREIRE, Paulo. Extensão ou comunicação? Rio de Janeiro: Paz e Terra, 2006.

JIMENEZ, C., \& MALGESINI, G.. Guía de conceptos sobre migraciones, racismo e interculturalidad. Madrid: La cueva del oso, 1997.

KELLER, Paulo F. O artesão e a economia do artesanato na sociedade contemporânea. Política \& Trabalho. Revista de Ciências Sociais, n.o 41, p. 323-347, out 2014.

LEMES. Sirlei. Aspectos da gestão econômica na atividade de bovinocultura. Dissertação/(Mestrado) São Paulo: Faculdade de Economia, Administração e Contabilidade da Universidade de São Paulo, 1996.

MARX, Karl. O capital: crítica da economia política: livro 1 - o processo de produção do capital. Rio de Janeiro: Civilização Brasileira, v. 1, n. 2, 1975.

MASCÊNE, Durcelice Cândida e TEDESCHI, Maurício. Termo de referência: atuação do Sistema SEBRAE no artesanato. Brasília: SEBRAE, 2010.

MERINO, M. D., e PRIVADO, J. (2015). Positive Psychological Functioning: Evidence for a new construct and its measurement. Anales de Psicología, v. 31, n. 1, p.45-54, 2015.

MINAYO, Maria Cecília de Souza. Importância da Avaliação Qualitativa combinada com outras modalidades de Avaliação. Saúde \& Transformação Social, Florianópolis, v.1, n. 3, p.02-11, 2011.

MONTEIRO, Sara; TAVARES, José; PEREIRA, Anabela. Adaptação portuguesa da escala de medida de manifestação de bem-estar psicológico com estudantes universitários - EMMBEP. Psicologia, Saúde \& Doenças. V. 13, n. 1, p.60-77, 2012.

\section{$7^{\circ}$ SDS S $_{2019}^{\mathrm{RECCF}}$}


NOVO, Rosa Ferreira. Bem-Estar e Psicologia: Conceitos e Propostas de Avaliação. RIDEP, v. 2, n.o 20, p.183-204, 2005.

PAOLIELLO, C. Relatório de Pós-doutoramento. Faculdade de Belas-Artes, Universidade de Lisboa, 2016.

PATROCÍNIO, Gabriel e NUNES, José Mauro. Design \& Desenvolvimento: 40 anos depois. São Paulo: Editora Blucher, 2015.

RANCIÈRE, Jacques. O mestre ignorante - cinco lições sobre a emancipação intelectual. Belo Horizonte: Autêntica, 2002.

ROCHE, Chris. Avaliação de impacto dos trabalhos de ONGs: aprendendo a valorizar as mudanças. São Paulo: Cortez, 2002.

RYFF, Carol D. Adult personality development and the motivation for per- sonal growth. In: D. Kleiber \& M. Maher (Eds.), Advances in Motivation and Achievement: Motivation and adulthood. Greenwich, CT: JAI Press, v. 4, p.55-92, 1985.

RYFF, Carol D.. Beyond Ponce de Leon and life satisfaction: New directions in quest for successful aging. International Journal of Behavioral Development, 12, p.35-55, 1989a.

RYFF, Carol. D.. Happiness is everything, or is it? Explorations on the meaning of psychological well-being. Journal of Personality and Social Psychology, 57, p.1069-1081, 1989b.

SENNETT, Richard. O artífice. Rio de Janeiro: Record, 2009.

SIQUEIRA, Mirlene Maria Matias e PADOVAM, Valquiria Aparecida Rossi. Bases Teóricas de BemEstar Subjetivo, Bem-Estar Psicológico e Bem-Estar no Trabalho. Psicologia: Teoria e Pesquisa, v. 24, n.․ 2, p.201-209, 2008.

TABOSA, Tibério César Macêdo, FERNANDES, Nelson da Cruz Monteiro, PAIVA JUNIOR, Fernando Gomes de. $\mathbf{O}$ fenômeno empreendedor coletivo e humanizado: a produção e a comercialização do artesanato bonecas solidárias de Gravatá/PE no mercado doméstico. Revista de Negócios, Blumenau, v. 15, n.으 3, p.11-28, jul/set 2010.

TUAN, Yi-Fu. Topofilia: um estudo da percepção, atitudes e valores do meio ambiente. São Paulo: Difel, 1980.

UNESCO. UNESCO Culture for Development Indicators - Cambodia's Technical Report. 2014. (https://en.unesco.org/creativity/sites/creativity/files/cdis/docs/cdis_technical_report_cambodia -0_2) 